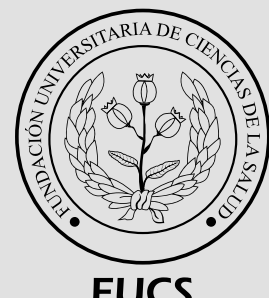

\title{
Positividad y proporción para muestras por COVID-19 en colombia
}

\section{Rate of positivity of COVID-19 testing in Colombia}

angeniero. Magister en Gestión de la Tecnología Educativa, Especialista en Administración de la Informática Educativa. Docente de matemáticas e Investigador, Secretaría de Educación de Soacha, Cundinamarca.

\section{R E S U M E N}

Introducción: a partir la aparición del brote del síndrome respiratorio agudo severo coronavirus 2 (SARS-CoV-2) en China, en diciembre de 2019, se ha ido propagando a nivel mundial la enfermedad del coronavirus 2019 (COVID-19) enfermedad causada por un nuevo coronavirus, el síndrome respiratorio agudo severo coronavirus 2. Objetivo: describir el comportamiento de positividad y proporción de muestras tomadas para SARS-CoV-2. Metodología: esta investigación se centró en las muestras de PCR procesadas para COVID-19, con la información proveniente del Instituto Nacional de Salud, en el periodo comprendido entre el 6 de marzo al 31 de octubre 2020. Resultados: se pudo evidenciar que el día que se tomó el mayor número de muestras fue el 24-07-2020, con 41.550, seguido del 23-07-2020 con 40.034, y el 22-07-2020 con 39.228 muestras. El día que se presentó el mayor número de muestra positivas fue el 21-07-2020 con 12.160, seguido del 23-07-2020 con 11.983, y 11.879 para el día 29-07-2020. Se apreció también que el 19-07-2020 se presentó la mayor proporción de positividad de las muestras tomadas con 0,33, seguido de 09-08-2020 con 0,32, continuando con el 30-08-2020 con 0,31. Conclusión: hay que seguir en la búsqueda activa de contagiados a través de la práctica de mayor número de pruebas de PCR, antígeno viral y molecular, esta última con un alto nivel de precisión, por parte de las EPS, y que estas a su vez aceleren el proceso de entrega de resultados a las personas.

Palabras clave: COVID-19, pruebas diagnósticas, SARS-CoV-2, pandemia

(C) 2020 Fundación Universitaria de Ciencias de la Salud - FUCS. Este es un artículo Open Access bajo la licencia CC BY-NC-ND (http://creativecommons.org/licenses/by-nc-nd/4.0/).

\section{INFORMACIÓN DEL ARTÍCULO}

Historia del artículo:

Fecha recibido: noviembre 10 de 2020 Fecha aceptado: noviembre 17 de 2020

\footnotetext{
Autor para correspondencia.

Jorge Enrique Díaz Pinzón jediazp@unal.edu.co
}

DOI

10.31260/RepertMedCir.01217372.1134 
Introduction: since the outbreak of severe acute respiratory syndrome coronavirus 2 (SARS-CoV-2) in China, on December 2019, the coronavirus 2019 (COVID-19) disease has been spreading worldwide. This disease is caused by a novel coronavirus, the severe acute respiratory syndrome coronavirus 2. Objective: to describe the positive rate of SARS-CoV-2 testing. Methodology: this research focused in PCR processing for COVID-19, using the information collected by the National Institute of Health, over the period between March 6 and October 31 2020. Results: we evidenced that the day in which the greatest number of samples were taken was 24-07-2020, with 41.550, followed by 40.034 samples taken on 23-07-2020, and 39.228 on 22-07-2020. The highest number of tests returning a positive result was reported on 21-07-2020 with 12.160, followed by 11.983 on 23-07-2020, and 11.879 on 29-07-2020. Likewise, the highest positive rate of 0.33 was evidenced on 19-072020 , followed by 0.32 on $09-08-2020$ and 0.31 on 30-08-2020. Conclusion: we must continue on the active search to identify infected people through conducting more PCR, and viral and molecular antigen tests, the latter offering a high level of accuracy, at the healthcare facilities (EPSs), which accelerate timely reporting to people.

Key words: COVID-19, diagnostic tests, SARS-CoV-2, pandemic.

(C) 2020 Fundación Universitaria de Ciencias de la Salud - FUCS. This is an open access article under the CC BY-NC-ND license (http://creativecommons.org/licenses/by-nc-nd/4.0/).

IN T ROD UCCIÓN

A partir la aparición del brote del síndrome respiratorio agudo severo coronavirus 2 (SARS-CoV-2) en Wuhan, China, en diciembre 20191, se ha ido propagando a nivel mundial, la enfermedad del coronavirus 2019 (COVID-19) es una enfermedad causada por un nuevo coronavirus, el síndrome respiratorio agudo severo coronavirus 2 (SARS-CoV-2). ${ }^{2}$

Los coronavirus son una causa del resfriado común, pero el SARS-CoV-2, que seguramente proviene de los murciélagos, causa una enfermedad más grave en muchos pacientes. ${ }^{3}$ Los síntomas más comunes contienen dolores musculares, fatiga, náuseas, vómitos y diarrea. Las personas también pueden tener pérdida o cambios en el sentido del gusto y el olfato. ${ }^{4}$ Ahora, la prueba estándar de oro de la reacción en cadena de la polimerasa (PCR) que se usa para diagnosticar COVID-19 requiere un proceso de laboratorio que a veces toma días, no minutos, para conseguir resultados debido a retrasos y escasez de suministros. Por lo tanto, un individuo podría ser negativo cuando se realiza la prueba, pero positivo en el momento en que se devuelve el resultado. ${ }^{5}$

La reacción cualitativa en cadena de la polimerasa en tiempo real de las secreciones nasofaríngeas es el criterio estándar para identificar los virus respiratorios, incluso el síndrome respiratorio agudo severo coronavirus 2 (SARS-CoV-2). ${ }^{6}$ Sin embargo, se han esbozado grandes preocupaciones con respecto a las tasas de resultados falsos negativos en los lugares de prueba de la comunidad. ${ }^{7}$

Las muestras de pacientes con sospecha de enfermedad por coronavirus 2019 (COVID-19) se someten a pruebas en tiempo real de la reacción en cadena de la polimerasa con transcriptasa inversa (RT-PCR) para la localización cualitativa del ARN del coronavirus 2 (SARS-CoV-2) del síndrome respiratorio agudo severo. La alta demanda de pruebas de RT-PCR para el SARS-CoV-2 durante la pandemia de
COVID-19 ha inducido escasez local, lo que ha llevado a los investigadores a meditar estrategias de pruebas en grupo. ${ }^{8}$ Es factible que algunas personas que sobreviven al COVID-19 tengan complicaciones significativas a largo plazo, incluidos trastornos respiratorios, cardíacos y de salud mental, y pueden tener un mayor riesgo de muerte prematura. Los datos de los sobrevivientes de COVID-19 apuntan que el menoscabo a largo plazo ocurre en aproximadamente un tercio de los sobrevivientes con enfermedad grave o crítica. ${ }^{9}$

No todas las personas que dan positivo al SARS-CoV-2 son infecciosas; quizás el $20 \%$ de las personas que dan positivo en la prueba tienen una infección lo suficientemente avanzada como para que las probabilidades de transmisión sean bajas. ${ }^{10}$ Además, aproximadamente el $25 \%$ de las personas que dan positivo probablemente no se pondrán en cuarentena. $^{11}$

\section{METODOLOGÍA}

El trabajo de investigación se realizó mediante un enfoque cuantitativo; la investigación cuantitativa es aquella en la que se acumulan y examinan datos cuantitativos sobre variables y estudia las propiedades y fenómenos cuantitativos. Según Hurtado y Toro (1998) citado por Díaz $^{12}$.

\section{POBLACIÓ N}

Esta investigación se centró en las muestras de PCR procesadas para COVID-19, con la información proveniente del Instituto Nacional de Salud ${ }^{13}$, en el periodo comprendido entre el 6 de marzo a 31 de octubre 2020. 


\section{RES ULTADOS}

En la figura 1 se aprecia que desde el registro del primer paciente contagiado por COVID-19 el 6 de marzo 2020, ha venido aumentando el número de pruebas PCR, alcanzando hacia el mes de julio 2020 el pico de muestras tomadas, de allí en adelante hasta el mes de octubre se ha presentado una disminución en la toma de muestras, los casos positivos guardan la misma relación que las muestras totales; hacia el mes de julio 2020 se presentó el pico de pruebas positivas para COVID-19, el día que se tomaron el mayor número de muestras fue 24-07-2020, con 41.550, seguido de 23-072020 con 40.034 , y 22-07-2020 con 39.228 muestras. El día que se presentó el mayor número de muestra positivas se ubicó el 21-07-2020 con 12.160, seguido de 23-07-2020 con 11.983, y 11.879 para el día 29-07-2020

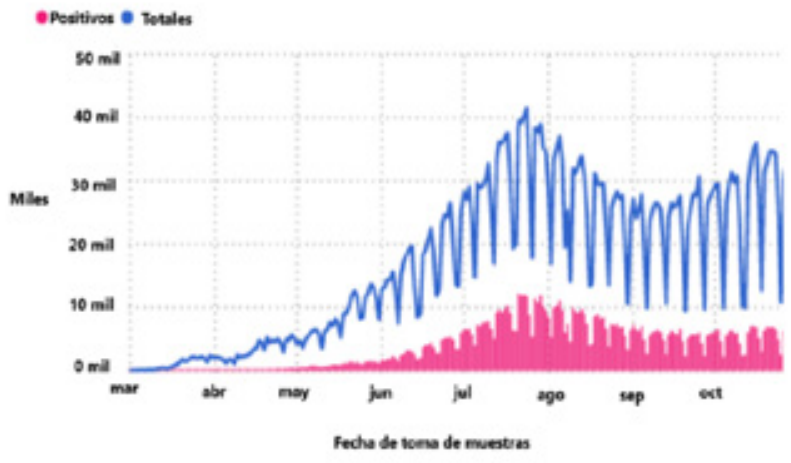

Fuente: Instituto Nacional de Salud.

Figura 1. Totales y positivos por fecha toma de muestras.

En la figura 2 se describe la proporción de positividad de las muestras tomadas por fecha, para calcular la proporción se procede de la siguiente manera: número de muestras positivas divido el número de muestras totales.

Por ejemplo, el 24-07-2020 se tomaron 41.550 muestras, las muestras positivas fueron para ese mismo día 11.773, $11.773 / 41.550=0,28$. Observamos también que el 19-072020 , se presentó la mayor proporción de positividad con 0,33 , seguido de 09-08-2020 con 0,32, continuando con el 30-08-2020 con 0,31.

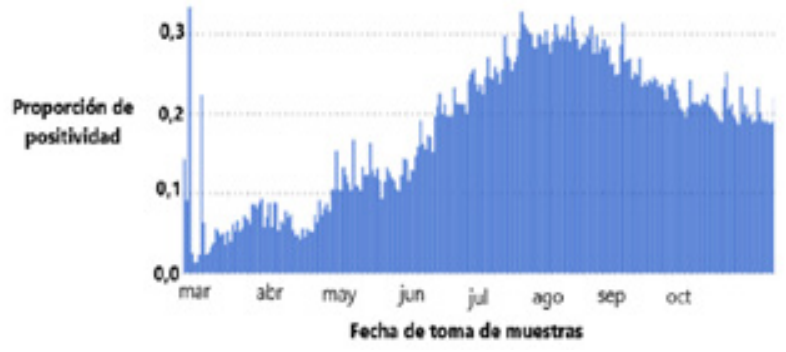

Fuente: Instituto Nacional de Salud.

Figura 2. Proporción de muestras positivas.

\section{CON CLUSIONES}

Se pudo evidenciar que el día que se tomó el mayor número de muestras fue 24-07-2020, con 41.550, seguido de 23-07-2020 con 40.034, y el 22-07-2020 con 39.228 muestras.

El día que se presentó el mayor número de muestras positivas se ubicó el 21-07-2020 con 12.160, seguido del 23-07-2020 con 11.983, y 11.879 para el día 29-07-2020. Se apreció también que el 19-07-2020, se presentó la mayor proporción de positividad de las muestras tomadas con 0,33, seguido de 09-08-2020 con 0,32, continuando con el 30-08-2020 con 0,31.

Hay que seguir en la búsqueda activa de contagiados a través de la práctica de mayor número de pruebas de PCR, antígeno viral y molecular, esta última con un alto nivel de precisión, por parte de las EPS, y que estas a su vez aceleren el proceso de entrega de resultados a las personas, para que de esta forma se pueda tener un dato real de intensidad de la transmisión y el contagio de la enfermedad, y proceder a realizar las respectivas medidas sanitarias y toma de decisiones terapéuticas amparadas para la ejecución de protocolos clínicos de actuación rápida.

Afín con Chaccour citado por Díaz ${ }^{14}$, las múltiples incertidumbres que a nivel biológico, clínico y epidemiológico subsisten en relación con este nuevo virus, lo que ya es evidente es que cada país ha reconocido o está reconociendo a la misma amenaza con diferentes medidas y/o con una mitigación diferente.

\section{DECLARACIÓN CONFLICTO DE INTERESES}

El autor declara no tener ningún conflicto de interes.

\section{REFEREN CIAS}

1. Rubín, R. The Challenges of Expanding Rapid Tests to Curb COVID-19. JAMA. 2020;324(18):1813-1815. doi: 10.1001/ jama.2020.21106

2. Center for Disease Control and Prevention. Interim Guidelines for Collecting, Handling, and Testing Clinical Specimens for COVID-19 (COVID-19) [Internet]. 2020 [Citado novirmbre] Recuperado de: https://www.cdc.gov/coronavirus/2019-ncov/ lab/guidelines-clinical-specimens.html

3. West $\mathrm{CP}$, Montori VM, Sampathkumar P. COVID-19 Testing: The Threat of False-Negative Results. 2020;95(6):11271129. doi: 10.1016/j.mayocp.2020.04.004

4. Yelin I, Aharony N, Shaer Tamar E, Argoetti A, et al. Evaluation of COVID-19 RT-qPCR test in multi-sample pools. Clin Infect Dis. 2020; ciaa531. doi: 10.1093/cid/ciaa531 
5. Organización Mundial de la Salud. Enfermedad por coronavirus (COVID-19): informe de situación 110 [Internet]. 2020 [citado noviembre 9]; Recuperado en: https://www.who.int/ docs/default-source/coronaviruse/situation-reports/20200509covid-19sitrep-110.pdf? sfvrsn = 3b92992c_4sitrep-110.pdf? sfvrsn = 3b92992c_4

6. Joost, W. Hallie, P. What Is COVID-19?. JAMA. 2020;324(8):816. doi: 10.1001/jama.2020.12984 doi: 10.1001 / jama.2020.12984.

7. Wiersinga WJ, Rhodes A, Cheng AC, et al. Pathophysiology, Transmission, Diagnosis, and Treatment of Coronavirus Disease 2019 (COVID-19): A Review. JAMA. 2020;324(8):782-793. doi: 10.1001/jama.2020.12839

8. Huynh PP, Ishii LE, Ishii M. What Is Anosmia?. JAMA. 2020;324(2):206. doi: 10.1001/jama.2020.109669.

9. Ahmed H, Patel K, Greenwood D, et al. Long-term clinical outcomes in survivors of coronavirus outbreaks after hospitalisation or icu admission: a systematic review and meta-analysis of follow-up studies. medRxiv. 2020. doi: $10.1101 / 2020.04 .16 .20067975$
10. Organización Panamericana de la Salud. COVID-19 y comorbilidades - AMÉRICAS: Herramienta práctica para estimar la población con mayornesgoy yiesgo alto de enfermedad grave por COVID-19 debido a condiciones de salud subyacentes en las Américas [Intemet]. 2020 [citado noviembre 9; Disponible en: https://www.paho.org/es/ documentos/covid-19-oomorbilidadesamericasantecedentes

11. Bilinski A, Mostashari F, Salomon JA. Modeling Contact Tracing Strategies for COVID-19 in the Context of Relaxed Physical Distancing Measures. JAMA Netw Open. 2020;3(8):e2019217. doi: 10.1001/ jamanetworkopen.2020.19217

12. Díaz-Pinzón, J.E. Correlación y regresión lineal de la evaluación tiempo y puntaje con recurso interactivo flash. INNOVA Research Journal. 2017;2(10):1-8. doi: 10.33890/innova.v2.n10.2017

13. Instituto Nacional de Salud. Coronavirus (COVID-2019) en Colombia [Internet]. Bogotá: Instituto Nacional de Salud; 2020 [citado 2020 octubre 28]. Recuperado de: https://www.ins.gov.co/Noticias/Paginas/Coronavirus.aspx.

14. Díaz Pinzón JE. Estudio comparativo entre el contagio durante la cuarentena obligada por el COVID-19 y el contagio durante la apertura gradual y controlada para algunos sectores de la economía en Colombia. Repert. Med. Cir. 2020;29(Supl. Núm.1):59-64. doi: 10.31260/RepertMedCir.01217372.1073 